\section{Bioinorganic Chemistry}

\section{7-11 July 2003, Santa María del Mar, Cuba}

The 2nd Santa María Workshop on Chemistry will be held at Santa María del Mar, a marvelous beach 24 km east of Old Havana. Organized by the University of Havana and the Cuban Chemical Society, the workshop will focus on Bioinorganic Chemistry. Papers in all aspects of this fascinating field of chemistry are welcomed, including metalloenzymes, radical scavengers, metal-based drugs, biomimetic systems, metal-DNA interactions, and physico-chemical characterization of bioinorganic systems. The workshop is intended to provide an international forum at which colleagues of the bioinorganic community may exchange results and points of view in a warm and pleasurable environment.

One of the main objectives of this workshop is to encourage the attention on Bioinorganic Chemistry in Latin America, especially among young scientists. In order to fulfill this goal, distinguished scientists from the USA and Europe have been confirmed as Plenary Lecturers: Ivano Bertini (Univ. Florence), Wolfgang Kaim (Univ. Stuttgart), Stephen Lippard (MIT), Jonathan Sessler (Univ. Texas-Austin), and Helmut Sigel (Univ. Basel).

\section{See Calendar on page 30 for contact information}

www.geocities.com/stamariaworkshop

\section{Degradation, Stabilization, and Recycling of Polymers}

\section{4-17 July 2003, Prague, Czech Republic}

The 42nd Microsymposium of P.M.M.: Degradation, Stabilization, and Recycling of Polymers is organized for experts from academia and industry interested in various aspects of polymer degradation and possible practical ways of its prevention. Emphasis will be placed on the latest achievements in research and industrial applications of polymer recycling. This meeting aims to provide an interdisciplinary forum for discussions concerning environmental degradation of plastics, ways of minimizing waste production, measures to stimulate reuse and recycling of polymers, and to contribute to the cross fertilization of ideas among polymer scientists and engineers.

\section{TOPICS}

- degradation, stabilization, and aging of polymers

- processing and melt stabilization of polymers, polymer blends, and composites

- testing and lifetime prediction of polymeric materials - polymer recycling-material and energy recovery

See Calendar on page 30 for contact information

www.imc.cas.cz/sympo/42micros.html

plants, animals, and humans.

The Society of Biological Inorganic Chemistry is the world's leading body for promoting this interdisciplinary field. Its members are scientific professionals from hospitals, research institutes, and universities engaged in research, development, and commercial activities. Fundamental knowledge has led to the development of bio-inspired photonic, electronic, and analytical techniques. For example, the glucose oxidase electrode developed for diabetics is the most frequently used analytical device in the world. The development of the famous platinum anticancer drug cis-Platin has also led to the search for new inorganic drugs for the treatment of cancer and other diseases. Radio-pharmaceuticals and other imaging agents, 
together with bio-sensors in general, constitute another burgeoning area of development.

The conference will provide attendees with the opportunity to showcase their ideas, developments, research, and products and to speak with each of the delegates at the conference. This conference has grown exponentially since its inception 20 years ago. There were 1300 delegates who attended the Tenth Conference in 2001 in Florence, Italy.
For more information contact: ICMS Pty Ltd

84 Queensbridge Street Southbank Vic 3006 Australia Tel.: +61396820244

Fax: +61396820288

E-mail: icbic11@icms.com.au

www.icms.com.au/icbicll

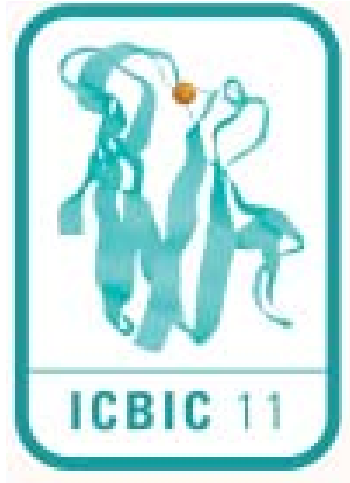

Molecular Characterization of Polymers

\section{4-28 August 2003, Bratislava, Slovakia}

The 17th Bratislava International Conference on Macromolecules: Molecular Characterization of Polymers will bring together academic and industrial researchers from around the world who are engaged in molecular characterization of synthetic and natural macromolecules. Current developments in separation methods and their applications will be discussed in detail. At this conference, traditionally held in Slovakia, approximately 17 plenary lectures and 50 contributed podium presentations are planned, with tutorials and reviews also included.

\section{See Calendar on page 31 for contact information}

\section{www.savba.sk/polymer/}

robbery or sexual assault, toxicogenetics for clinical and forensic toxicology. Workshops, oral sessions, and breakfast roundtables will also be included.

A two-day satellite workshop entitled New Advances in Model-Based, Goal-Oriented Optimal Individualized Drug Therapy: Relationship To Population PK/PD Modelling and to Multiple Model Methods for Optimal Tracking of Drug Behavior and Optimal Dosage Design will be held 12-13 September. This course is intended for physicians, pharmacists, clinical toxicologists, and biomedical scientists with an interest in population pharmacokinetic and pharmacodynamic modelling and in therapeutic drug monitoring and optimal individualization of drug therapy for patient care.

For more information contact:

Congress Plus GmbH

Rosemarie B. Marty

Schwarzwaldallee 215

Postfach $\mathrm{CH}-4016$ Basel, Switzerland

Tel.: 41616831382

Fax: 41616831383

E-mail: info@congress-plus.ch or info@ictdmct2003.ch

\section{www.ictdmct2003.ch}

